\title{
Quality of life in head and neck cancer patients at 5 years after free flap reconstruction: a significant decline during the follow-up
}

\author{
Sanna Lahtinen ${ }^{1,2} \cdot$ Krisztina Molnár $^{1,2} \cdot$ Siiri Hietanen $^{2} \cdot$ Petri Koivunen $^{3,5} \cdot$ Pasi Ohtonen $^{2,4} \cdot$ Antti Alakärppä ${ }^{3,5}$. \\ Janne Liisanantti ${ }^{1,2}$ (1)
}

Received: 18 October 2021 / Accepted: 23 December 2021 / Published online: 5 January 2022

(c) The Author(s) 2022

\begin{abstract}
Purpose Free flap reconstructions following head and neck tumor resection are known to involve more than 50\% rate of complications and other adverse events and up to $50 \%$ mortality during a 5-year follow-up.

We aimed to examine the difference in the long-term quality of life (QoL) between the 2-year and 5-year assessments after free flap surgery for cancer of the head and neck.

Methods A total of 28 of the 39 eligible patients responded to the survey. QoL was assessed at 5 years after operation and compared with the assessment performed at 2 years after the operation using RAND-36, EORTC-C 30 and H\&N-35, and SWAL-QOL tools.

Results The criteria for poor QoL using RAND-36 tool was met in 11 (39.3\%) patients in contrast to $4(14.3 \%, P=0.003)$ patients in the 2-year assessment. EORTC-C30 global score was decreased from 83.9 (SD16.4) to 64.6 (SD 24.0, $P<0.001$ ) during the follow-up. In both RAND-36 and EORTC-C30 surveys, decline was found in physical and role functioning together with energy and emotional well-being domains. SWAL-QOL showed poor swallowing-related QoL in both assessments. Conclusion We found a significant decline in QoL during a 5-year follow-up after free flap surgery for cancer of the head and neck.
\end{abstract}

Keywords Cancer of the head and neck $\cdot$ Free flap surgery $\cdot$ Quality of life $\cdot$ Long-term follow-up

\section{Introduction}

Free-flap reconstructions following head and neck tumor resection are known to involve more than $50 \%$ of complication and other adverse events rate, and up to $50 \%$ mortality

Krisztina Molnár and Siiri Hietanen have contributed equally to this work.

Janne Liisanantti

janne.liisanantti@ppshp.fi

1 Department of Anesthesiology, Oulu University Hospital (OYS), P.O. BOX 21, 90029 Oulu, Finland

2 Research Group of Surgery, Anesthesiology and Intensive Care, MRC Oulu, Oulu, Finland

3 Department of Otorhinolaryngology and Head and Neck Surgery, Oulu University Hospital, Oulu, Finland

4 Department of Operative Care, Oulu University Hospital, Oulu, Finland

5 PEDEGO Research Unit, MRC Oulu, Oulu, Finland during a 5-year follow-up [1,2]. The most dominant factors affecting the long-term outcome are patient related, such as postoperative medical complications and comorbidities [1, 2]. Especially, postoperative medical complications, including pneumonia, myocardial infarction or stroke have negative impact on both long-term outcome and quality of life (QoL) [2,3].

It is previously demonstrated that QoL assessed with RAND-36 tool 2 years after the free flap operation is comparable with QoL of general population in patients without postoperative complications [3]. Other studies using different tools, such as EORTC QLQ-C30 have shown similar results [4-6]. Both patient- and treatment-related factors have shown to be linked to the assessed QoL [5, 6]. According to our knowledge, most of the previous studies have reported the evaluations only up to 2 years after the operation and the number of studies focusing on the QoL in a longer follow-up is limited. In one Finnish survey, the QoL was assessed with 15D-tool and the study showed a reduction in the QoL during a 5-year follow-up [7]. 
We determined to examine the QoL at 5 years after the primary operation and to compare the measured QoL to the assessment performed at 2 years after operation using RAND-36-, EORTC-C30-, EORTC-HNC35-, and SWALQtools. In addition, we wanted to examine the impact of the recorded postoperative complications on the long-term QoL.

\section{Materials and methods}

This prospective cross-sectional cohort study was conducted one of the five University Hospitals in Finland, providing tertiary care for patients undergoing free flap surgery due to cancer of the head and neck. The study protocol was accepted by the hospital administration (239/2016) and local ethics committee (The Regional Ethics Committee 95/2016).

\section{Patients}

The original cohort consisted of all the 542 -year survivors operated with free flap reconstruction during the period 2013-2016. One patient was excluded for not being eligible (3). The patients' QoL was assessed at 2 years after the operation during the period 2017-2018 (baseline assessment). Of the original cohort, 39 patients were alive, and 28 patients responded to the long-term QoL assessment at 5 years after the operation. Two patients were in palliative care, and therefore, not contacted, and nine patients did not respond to the survey.

\section{Assessments}

Baseline assessment was performed at 2 years after the operation either by interview during normal control visit or by letter. For the 5-year assessment, the patients alive were contacted by telephone or SMS, after which the questionnaires were sent to them. RAND-36, EORTC-QLQ-C30, EORTC-QLQ-H\&N-C35 and SWAL-QOL- questionnaires were used to assess the QoL. Beck depression inventory (BDI) was used to assess depression [8]. In the BDI score of 7 or more was considered clinically significant.

\section{RAND-36}

RAND-36 is a general measure of health and well-being consisting of eight domains (general health, physical functioning, physical and emotional role functioning, emotional well-being, social functioning, pain, energy/fatigue) scored in a scale from 0 (the worst) to 100 (the best) [9]. There are Finnish age-adjusted RAND-36 reference values available and these were used for comparison [10]. Poor QOL in each domain was determined as a difference of more than -2 SD compared with the age-adjusted reference values. The overall QoL was considered poor if one or more of the domains met the criteria.

\section{EORTC-QLQ-C30 \& EORTC QLQ-H\&N35}

EORTC QLQ-C30 is a questionnaire used for evaluating the general QOL among cancer patients. The questionnaire consists of five functioning scales, three symptom scales, a global QOL scale, and six single items assessing other symptoms and problems often reported by cancer patients. EORTC QLQ-H\&N35 is a tumor-specific QOL questionnaire specially designed for head and neck cancer patients. This questionnaire includes seven symptom scales, six single items, and five optional items that evaluate the impact of tumor location and treatment on QOL. The scales and single-item scores of both EORTC instruments are linearly transformed into a score of 0-100. A high scores from the functional scale and the global QOL scale represents a high level of functioning, whereas a high score from the symptom scale or a single item represents a high level of symptoms $[11,12]$.

\section{SWAL-QOL}

SWAL-QOL consists of 44 questions assessing ten QOL domains: food selection, burden, mental health, social functioning, fear, eating duration, eating desire, communication, sleep, and fatigue. Sleep and fatigue contribute to general QOL, whereas the other domains are contributors to dysphagia-specific QOL. For analyzing the results, each scale is constructed using Likert's method, which equally weighs each item and sums them into an overall scale score. All scales are transformed to a $0-100$ metric, 100 indicating the most favorable state and 0 the least favorable, and scores in between representing the percentage of the total possible score achieved. SWAL-QOL is developed to assess the impact of oropharyngeal dysphagia in neurologic diseases but has also been used in other conditions causing swallowing problems, i.e., head and neck cancer. The total SWALQOL score includes 23 items from 7 domains (communication, sleep and fatigue excluded). A cut-off value of 86 is used to determine significant impairment of the swallowingrelated QOL [13].

\section{Statistical analysis}

Statistical analysis was performed using SPSS for Windows (IBM Corp., IBM SPSS Statistics for Windows, version 25, Armonk, NY, USA). Categorical variables are presented as number $(n)$ and percentage $(\%)$ and continuous variables in mean and standard deviations (SD). Differences between the QoL assessments were tested using paired samples $t$ test. Continuous variables were tested using Mann-Whitney test 
and categorical values using Fisher's exact test. $P$ value less than 0.05 was considered statistically significant.

\section{Results}

The QoL assessment was performed at 5.3 (SD 0.9) years from the operation and mean time between the assessments was 2.9 (SD 0.5) years. The criteria for poor QoL was met in $11(39.3 \%)$ patients. In the baseline assessment the criteria for poor QoL was met in $4(14.3 \%, P=0.003)$ patients. Patients with poor QOL were older compared with those with good QoL. There were no differences between groups in other demographic factors (Table 1).

\section{RAND-36}

The comparison between the 2-year and 5-year evaluations showed significant reduction in all the RAND-36 domains except role functioning. The measured RAND-36 values were lower than the general population values in all the domains except energy/fatigue (Table 2). Postoperative complications did not have an impact on the RAND-36 assessments at 5 years after the operation (Table 3 ).

\section{EORTC-C30 \& EORTC- H\&N35}

The global health status and all the functional scales declined significantly between the 2-year and 5-year assessments. There was increase in symptom scales of fatigue, pain, and diarrhea. Of the EORTC-H\&N35 dimensions, there was increase in symptom scales of social eating, social contact, less sexuality, and felt ill. There was decrease in scales of pain killers and sensing problems (Table 4).

\section{SWAL-QOL}

There were no differences between the 2-year and 5-year SWAL-QOL- evaluations. The SWAL-QOL total score was 66.3 (Table 5).

\section{Discussion}

The main finding of the present study is a significant reduction in the quality of life during the 3-year follow-up discovered using the RAND-36 tool. The rate of respondents reporting poor QoL increased more than two-fold during the 3-year follow-up. In addition, a reduction was seen in functional scales assessed with EORTC QLQ-30 tool. The swallowing-related QoL did not change over the time, however, most of the dimensions were scored low at the baseline assessment. Finally, according to the BDI score more than half of the respondents had signs of depression, however, this was not associated with poor QoL.

There is a limited number of previous studies focusing on long-term QoL in head and neck cancer survivors operated with free flap reconstruction. The present results are in line with the results reported by relatively recent Finnish study with a narrower range of assessments [7]. The probable reason for limited number of studies is the high mortality in this patient group but also the small cohorts limiting the possibilities for long-term follow-up.

The significant reduction in QoL can be explained by several factors. First, the patients were approximately 3 years older than during the baseline assessment and thus it is likely that other comorbidities as well as aging may have had an impact on the measured QoL. It has been shown previously that high utilization of health care resources is related to poor QoL measured using RAND-36 tool [10] Second, the decline in the QoL could be explained by the disease progression; the 5-year mortality has been reported to be more than $50 \%$ in this patient group and majority of these patients die due to cancer of the head and neck $[1,2,14]$. However, the present study setting does not allow us to confirm this hypothesis. Third, in our previous assessment, the measured QoL was comparable with the general population values [3] and one could hypothesize that at the 2-year assessment the respondents reported good QoL simply due to satisfaction for surviving. At the 5 -year assessment they have achieved a steady state in the recovery and factors having a negative impact on the QoL become more prominent. For instance, the swallowingrelated QoL was comparable between the assessments but at 5 years from the operation, it might be more important. However, this study setting does not allow us to confirm this hypothesis.

The measured BDI scores in the current study population indicated high rate of depression. We also showed a significant decline in all used QoL tools in mental health dimensions. This supports our hypothesis that at the 5-year assessment the patients' life has changed from the winning the disease to living with the disease with its limitations to the daily life. These include decline in dimensions focusing on the social life and physical functioning as well as experienced general health. In the 2-year assessment the recorded medical complications had a significant negative impact on QoL, while surgical complications did not have an impact on the QoL [3]. As the medical complications have been associated with the long-term mortality, it is obvious that these patients were not included in the present cohort [2]. Surgical complications are more often operation related and these are prone to recover. This explains the absence of impact of the postoperative complications on the long-term QoL. 
Table 1 Patient characteristics and quality of life assessments of the 28 patients operated with free flap reconstruction for cancer of the head and neck

\begin{tabular}{|c|c|c|c|c|}
\hline & Interviewed $n=28$ & $\begin{array}{l}\text { Good QoL } \\
N=17\end{array}$ & $\begin{array}{l}\text { Poor QoL } \\
N=11\end{array}$ & $P$ value \\
\hline Age at assessment (y) & $68.3(9.7)$ & $66.4(9.0)$ & $71.2(10.5)$ & 0.047 \\
\hline \multicolumn{5}{|l|}{ Perioperative data } \\
\hline Gender $\mathrm{f} / \mathrm{m}$ & $19 / 9$ & $12 / 5$ & $7 / 4$ & 0.507 \\
\hline \multicolumn{5}{|l|}{ ASA } \\
\hline $1-2$ & $17(60.7)$ & $12(70.6)$ & $5(45.5)$ & 0.175 \\
\hline $3-4$ & $11(39.3)$ & $5(29.4)$ & $6(54.5)$ & \\
\hline $\mathrm{CCI}>1$ & $11(39.3)$ & $5(29.4)$ & $6(54.5)$ & 0.175 \\
\hline Smoking & $11(39.3)$ & $8(47.1)$ & $3(27.3)$ & 0.260 \\
\hline Alcohol abuse & $3(10.7)$ & $1(5.9)$ & $2(18.2)$ & 0.336 \\
\hline BMI & $25.1(5.5)$ & $24.6(6.3)$ & $25.9(4.4)$ & 0.352 \\
\hline \multicolumn{5}{|l|}{ Tumor } \\
\hline Oral cavity/tongue & $12(42.9)$ & $8(47.2)$ & $4(36.4)$ & \\
\hline Maxilla & $4(14.3)$ & $1(5.9)$ & $3(27.3)$ & \\
\hline Mandibula & $3(10.7)$ & $1(5.9)$ & $2(18.2)$ & \\
\hline Larynx/pharynx & $1(3.6)$ & $1(5.9)$ & 0 & \\
\hline Palatinal & $4(14.3)$ & $2(11.8)$ & $2(18.2)$ & \\
\hline Buccal mucosa & $3(10.7)$ & 3 17.6) & 0 & \\
\hline Others & $1(3.6)$ & $1(5.9)$ & 0 & \\
\hline \multicolumn{5}{|l|}{ Free flap } \\
\hline RFA & $14(50.0)$ & $7(41.2)$ & 7 (63.6) & \\
\hline ALT & $2(7.1)$ & $2(11.8)$ & 0 & \\
\hline Scapula & $1(3.6)$ & 0 & $1(9.1)$ & \\
\hline Fibula & $4(14.3)$ & $4(23.5)$ & $4(14.3)$ & \\
\hline Lateral arm & $6(21.4)$ & $4(23.5)$ & $2(18.2)$ & \\
\hline Crista & $1(3.6)$ & 0 & $1(9.1)$ & \\
\hline Tracheostomy & $23(82.1)$ & $16(94.1)$ & $8(72.7)$ & 0.157 \\
\hline Neck dissection & $22(78.5)$ & $14(82.4)$ & $8(72.7)$ & 0.439 \\
\hline Complication & $12(42.9)$ & $9(52.9)$ & $3(27.3)$ & 0.172 \\
\hline Surgical complication & $11(39.3)$ & $8(47.1)$ & $3(27.3)$ & 0.260 \\
\hline Medical complication & $6(21.4)$ & $4(23.5)$ & $2(18.2)$ & 0.561 \\
\hline \multicolumn{5}{|l|}{ Baseline assessment } \\
\hline Poor baseline QoL & $4(14.3)$ & $1(6.7)$ & $3(23.1)$ & 0.09 \\
\hline EORTC global score & $83.9(16.3)$ & $84.3(17.6)$ & $83.3(14.9)$ & 0.209 \\
\hline 6 min walking test* & $101.2(16.0)$ & $105.0(17.6)$ & $95.9(12.6)$ & $>0.9$ \\
\hline Hand grip test & $29.2(12.3)$ & $28.9(10.1)$ & $29.6(29.2)$ & 0.561 \\
\hline \multicolumn{5}{|l|}{ 5-year assessment } \\
\hline Time from the operation, years & $5.3(0.9)$ & $5.3(0.9)$ & $5.0(0.9)$ & 0.429 \\
\hline Time between the assessments & $2.9(0.5)$ & $3.0(0.5)$ & $2.7(0.4)$ & 0.331 \\
\hline EORTC global score & $64.6(24.0)$ & $71.2(25.5)$ & $54.5(18.0)$ & 0.07 \\
\hline SWQL $<86$, data missing 5 & $18(78.3)$ & $10(76.9)$ & $8(80.0)$ & 0.633 \\
\hline BDI score $>7$ & $14(53.8)$ & $8(50.0)$ & $6(60.0)$ & 0.464 \\
\hline BDI & $10.4(8.2)$ & $8.3(6.8)$ & $13.8(9.7)$ & 0.317 \\
\hline
\end{tabular}

*Percentages of age-adjusted normal score

\section{Clinical impact}

The current study showed the significant reduction in QoL reported at 5 years after free flap surgery due to cancer of the head and neck. We have previously reported that chronic comorbidities as well as the medical complications were related to poor outcome. The medical complications were more common among those patients who had poor QoL at 2 years after the operation [2,3]. The respondents of this study did not face the medical complications postoperatively 
Table 2 Differences in RAND-36 dimensions between assessments at 2 years and 5 years after free flap surgery for cancer of the head and neck

\begin{tabular}{lllllll}
\hline Dimension & 5-year value & Baseline & Difference & $P$ value & $\begin{array}{l}\text { General value } \\
\text { Number of responders answer- } \\
\text { ing below age-adjusted refer- } \\
\text { ence }\end{array}$ \\
\hline Physical functioning & $68.0(27.0)$ & $86.1(21.8)$ & $-18.0(-25.5$ to -10.5$)$ & $<0.00184 .9(22.1)$ & $12(35.7)$ \\
Role functioning physical & $58.3(41.6)$ & $76.4(27.8)$ & $-18.1(34.3$ to -1.8$)$ & $0.03174 .8(35.5)$ & $10(35.7)$ \\
Role functioning emotional & $65.4(42.8)$ & $79.0(30.9)$ & $-13.6(31.6$ to -4.4$)$ & $0.13375 .0(36.4)$ & $13(16.4)$ \\
Energy/fatigue & $60.4(23.9)$ & $78.9(14.9)$ & $-18.5(25.7$ to -11.3$)$ & $<0.00164 .0(22.4)$ & $10(35.7)$ \\
Emotional well-being & $75.1(17.5)$ & $85.8(11.4)$ & $-10.7(17.3$ to -4.0$)$ & $0.00373 .7(19.7)$ & $11(39.3)$ \\
Social functioning & $70.1(26.9)$ & $85.3(18.3)$ & $-15.2(27.2$ to -3.1$)$ & $0.01582 .1(23.2)$ & $16(57.1)$ \\
Pain & $66.6(25.5)$ & $81.1(19.3)$ & $-14.5(-23.9$ to -5.0$)$ & $0.00476 .2(24.0)$ & $13(46.4)$ \\
General health & $52.2(21.8)$ & $63.1(19.9)$ & $-10.9(-17.9$ to 3.9) & $0.00365 .0(19.8)$ & $10(35.7)$ \\
\hline
\end{tabular}

Table 3 RAND-36 values of 28 patients with and without complications after free flap surgery for cancer of the head and neck in comparison with RAND-36 values of general Finnish population

\begin{tabular}{lllll}
\hline & Complications & No complications & $P$ value & General population \\
\hline Physical functioning & $633(27.0)$ & $71.6(27.4)$ & 0.397 & $84.9(22.1)$ \\
Role functioning physical & $72.7(30.5)$ & $48.4(46.1)$ & 0.195 & $74.8(35.5)$ \\
Role functioning emotional & $84.8(27.3)$ & $52.1(47.1)$ & 0.089 & $75.0(36.4)$ \\
Energy/fatigue & $64.1(17.8)$ & $57.8(27.1)$ & 0.610 & $64.0(22.4)$ \\
Emotional well-being & $76.4(13.7)$ & $74.3(20.1)$ & 0.981 & $73.7(19.7)$ \\
Social functioning & $67.7(25.3)$ & $71.9(28.7)$ & 0.599 & $82.1(23.2)$ \\
Pain & $63.1(18.2)$ & $69.2(30.2)$ & 0.371 & $76.2(24.0)$ \\
General health & $51.8(25.8)$ & $52.5(19.5)$ & 0.790 & $65.0(19.8)$ \\
\hline
\end{tabular}

and they reported good QoL at 2 years after the operation. Disease progression and ageing as factors having negative impact on the QoL are not controllable. Problems in social functions, such as eating and communication, as well as in mental well-being are important factors causing deterioration of the QoL. These patients could benefit from support in daily-life activities, for instance psycho-social support and dietician consultations during the follow-up. Moreover, peer support might be beneficial for the patients suffering from several symptoms.

\section{Limitations}

This study was limited by the low number of patients. In the previous assessment, we were able to recruit nearly $100 \%$ of the operated patients, but in this survey, the participants represented $72.0 \%$ of the survivors, which could be considered as a limitation. Furthermore, we did not take into account other factors that may have had an impact on the QoL, such as comorbidities or other diseases requiring operative care. Also, the baseline screening of depression would have been interesting in terms of follow-up data. We did not include pre- and postoperative radiation into the analysis, which may have had an impact on the results, especially in the swallowing-related QoL. The number of patients receiving radiation therapy would have been modest since in our previous study the rate of radiation therapy was approximately $30 \%$ resulting in ten possible patients in this cohort [2]. Finally, the perioperative data were collected retrospectively, which can be considered as a limitation even though the operative care was provided at 5 years before the assessment and thus probably played a minor role in the current situation of the respondents.

\section{Conclusion}

We found a significant reduction in QoL between the 2-year and 5-year assessments in patients who had been operated with free flap reconstruction due to cancer of the head and neck. The patients and treating physicians should be aware of possible treatment- and disease-related adverse effects in long-term follow-up. Decreases in mental health and social as well as physical functioning explained most of the decline in the quality of life. Intraoperative factors and postoperative complications did not have an impact on the measured QoL. 
Table 4 Differences in EOTC-C30 and EORTC

H\&N35 dimensions between assessments at baseline and at 5 years after free flap surgery for cancer of the head and neck

\begin{tabular}{|c|c|c|c|c|}
\hline Dimension & 5-year value & Baseline & Difference & $P$ value \\
\hline \multicolumn{5}{|l|}{ EORTC-C30 } \\
\hline Global health status & $64.6(24.0)$ & $83.9(16.4)$ & $-19.3(-27.6$ to 11.07$)$ & $<0.001$ \\
\hline \multicolumn{5}{|l|}{ Functional scales } \\
\hline Physical functioning & $71.4(22.6)$ & $86.0(18.2)$ & $-14.6(-11.0$ to -8.6$)$ & $<0.001$ \\
\hline Role functioning & $82.1(22.2)$ & $91.1(18.4)$ & $-8.9(17.8$ to -0.05$)$ & 0.049 \\
\hline Emotional functioning & $84.2(16.3)$ & $90.5(11.5)$ & $-6.3(-12.0$ to -0.5$)$ & 0.034 \\
\hline Cognitive functioning & 81.5 (21.9) & $90.5(11.5)$ & $-8.9(-15.1$ to -2.7$)$ & 0.007 \\
\hline Social functioning & $81.0(18.6)$ & $89.9(12.3)$ & $-8.9(19.3$ to -1.4$)$ & 0.087 \\
\hline \multicolumn{5}{|l|}{ Symptom scales } \\
\hline Fatigue & $30.2(20.5)$ & $13.1(15.7)$ & $17.1(11.0$ to 23.1$)$ & $<0.001$ \\
\hline Nausea and vomiting & $4.5(11.9)$ & $1.8(5.2)$ & $2.7(-1.6$ to 7.0$)$ & 0.213 \\
\hline Pain & $29.8(23.3)$ & $14.9(16.6)$ & $14.9(7.3$ to 22.4$)$ & $<0.001$ \\
\hline Dyspnea & $15.5(24.8)$ & $10.7(24.1)$ & $4.8(-2.0$ to 14.6$)$ & 0.161 \\
\hline Insomnia & $28.6(25.2)$ & $19.0(24.7)$ & 9.5 (1.0 to 18.0$)$ & 0.030 \\
\hline Appetite loss & $9.5(20.0)$ & $3.6(10.5)$ & $6.0(-2.7$ to 14.6$)$ & 0.170 \\
\hline Constipation & $13.1(22.8)$ & $8.3(14.7)$ & $4.8(-5.6$ to 15.1$)$ & 0.355 \\
\hline Diarrhea & $9.5(17.8)$ & $2.4(8.7)$ & $7.1(0.7$ to 13.6$)$ & 0.031 \\
\hline Financial difficulties & $15.5(24.8)$ & $13.1(22.8)$ & $2.4(-6.9$ to 11.6$)$ & 0.602 \\
\hline \multicolumn{5}{|c|}{ EORTC H\&N35 symptom scales } \\
\hline Pain & $22.0(20.2)$ & $17.6(17.9)$ & 4.5 (1.0 to 9.9$)$ & 0.105 \\
\hline Swallowing & $23.1(23.4)$ & $16.7(21.8)$ & $3.5(-4.1$ to 11.2$)$ & 0.354 \\
\hline Senses problems & $11.3(20.8)$ & $16.7(21.8)$ & $-5.4(-10.0$ to -0.7$)$ & 0.026 \\
\hline Speech problems & $27.2(20.3)$ & $20.2(21.8)$ & $7.0(-0.5$ to 14.5$)$ & 0.067 \\
\hline Trouble with social eating & $11.1(21.2)$ & $27.5(27.5)$ & $-16.4(-29.4$ to -33$)$ & 0.016 \\
\hline Trouble with social contact & $18.8(16.9)$ & $11.0(13.2)$ & $7.8(3.3$ to 12.4$)$ & 0.001 \\
\hline Less sexuality & $51.3(41.1)$ & $26.7(32.6)$ & 24.7 (7.7 to 41.6$)$ & 0.006 \\
\hline Teeth & $29.8(35.5)$ & $29.8(37.7)$ & $0(-18.6$ to 18.6$)$ & $>0.9$ \\
\hline Opening mouth & $39.3(37.7)$ & $32.1(34.5)$ & $7.1(-5.7$ to 20.0$)$ & 0.264 \\
\hline Dry mouth & $39.3(32.8)$ & $44.0(34.0)$ & $-4.7(-18.3$ to 8.7$)$ & 0.475 \\
\hline Sticky saliva & $32.1(34.5)$ & $23.8(31.2)$ & $8.3(-4.2$ to 20.8$)$ & 0.183 \\
\hline Coughing & $21.4(25.4)$ & $9.5(17.8)$ & $11.9(2.5$ to 21.4$)$ & 0.015 \\
\hline Felt ill & $23.8(25.4)$ & $6.0(17.8)$ & 17.9 (8.9 to 26.8$)$ & $<0.001$ \\
\hline Pain killers & $16.7(17.0)$ & 35.7 (48.9) & $-19.0(-36.1$ to -2.0$)$ & 0.030 \\
\hline Nutritional supplements & $13.1(16.6)$ & $25.0(21.0)$ & $-11.9(-28.9$ to 5.0$)$ & 0.161 \\
\hline Feeding tube & $10.7(31.5)$ & $3.6(10.5)$ & $7.1(1.0$ to 15.3$)$ & 0.083 \\
\hline Weight loss & $3.6(10.5)$ & $3.6(18.9)$ & $0.0(-8.6$ to 8.6$)$ & 1.0 \\
\hline Weight gain & $4.8(11.9)$ & $17.9(39.0)$ & $-13.1(-28.6$ to 2.4$)$ & 0.094 \\
\hline
\end{tabular}


Table 5 Differences in SWALQOL dimensions between assessments at baseline and at 5 years after free flap surgery for cancer of the head and neck

\begin{tabular}{lllcc}
\hline & 5-year value & Baseline & Difference & $P$ value \\
\hline Burden & $66.6(31.5)$ & $68.0(34.2)$ & $-1.4(-19.5$ to 16.6$)$ & 0.870 \\
Eating duration & $41.3(23.6)$ & $36.5(31.2)$ & $4.8(-11.5$ to 21.1$)$ & 0.550 \\
Eating desire & $76.1(24.5)$ & $81.7(23.9)$ & $-5.6(-19.5$ to 8.3$)$ & 0.412 \\
Symptom frequency & $69.2(21.0)$ & $75.7(15.1)$ & $-6.6(-17.2$ to 4.1$)$ & 0.215 \\
Food selection & $69.3(31.0)$ & $75.7(15.1)$ & $-10.2(-25.9$ to 5.5$)$ & 0.191 \\
Communication & $94.6(21.0)$ & $74.0(23.1)$ & $-12.4(-26.2$ to 1.3$)$ & 0.075 \\
Fear of eating & $87.5(18.3)$ & $91.3(13.2)$ & $-6.7(-16.6$ to 3.0$)$ & 0.169 \\
Mental health & $74.5(30.3)$ & $80.6(24.8)$ & $-6.1(-22.7$ to 10.4$)$ & 0.451 \\
Social eating & $70.0(39.3)$ & $77.6(26.8)$ & $-7.6(-26.8$ to 11.6$)$ & 0.422 \\
Fatigue & $69.0(24.9)$ & $80.7(17.1)$ & $-11.7(-19.3$ to -4.0$)$ & 0.005 \\
Sleep & $64.5(26.1)$ & $72.5(29.1)$ & $-8.0(-26.5$ to 10.6$)$ & 0.385 \\
SWAL-QOL total & $66.3(22.0)$ & $76.8(17.2)$ & $-10.57(-22.9$ to 1.7$)$ & 0.088 \\
\hline
\end{tabular}

Funding Open Access funding provided by University of Oulu including Oulu University Hospital. This study was funded by Thelma Mäkikyrö fund.

\section{Declarations}

Conflict of interest None of the authors report conflict of interest.

Open Access This article is licensed under a Creative Commons Attribution 4.0 International License, which permits use, sharing, adaptation, distribution and reproduction in any medium or format, as long as you give appropriate credit to the original author(s) and the source, provide a link to the Creative Commons licence, and indicate if changes were made. The images or other third party material in this article are included in the article's Creative Commons licence, unless indicated otherwise in a credit line to the material. If material is not included in the article's Creative Commons licence and your intended use is not permitted by statutory regulation or exceeds the permitted use, you will need to obtain permission directly from the copyright holder. To view a copy of this licence, visit http://creativecommons.org/licenses/by/4.0/.

\section{References}

1. McMahon JD, MacIver C, Smith M et al (2013) Postoperative complications after major head and neck surgery with free flap repair-prevalence, patterns, and determinants: a prospective cohort study. Br J Oral Maxillofac Surg 51:689-695

2. Lahtinen S, Koivunen P, Ala-Kokko T et al (2018) Complications and outcome after free flap surgery for cancer of the head and neck. Br J Oral Maxillofac Surg 56:684-691

3. Lahtinen S, Koivunen P, Ala-Kokko T et al (2018) Quality of life after free flap surgery for cancer of the head and neck in patients with or without postoperative complications. Eur Arch Otorhinolaryngol 275:2575-2584

4. Borggreven PA, Aaronson NK, Verdonck-de Leeuw IM et al (2006) Quality of life after surgical treatment for oral and oropharyngeal cancer: a prospective longitudinal assessment of patients reconstructed by a microvascular flap. Oral Oncol 43:1034-1042

5. Bozec A, Poissonnet G, Chamorey E et al (2008) Free-flap head and neck reconstruction and quality of life: a 2-year prospective study. Laryngoscope 118:874-880

6. Momeni A, Kim RY, Kattan A et al (2013) Microsurgical head and neck reconstruction after oncologic ablation: a study analyzing health-related quality of life. Ann Plast Surg 70:462-469

7. Kainulainen S, Koivusalo AM, Roine RP et al (2020) Long-term quality of life after surgery of head and neck cancer with microvascular reconstruction: a prospective study with 4.9-years followup. Oral Maxillofac Surg 24:11-17

8. Beck AT, Steer RA (1984) Internal consistencies of the original and revised beck depression inventory. J Clin Psychol 40:1365-1367

9. Hays RD, Sherbourne CD, Mazel RM (1993) The rand 36-item health survey 1.0. Health Econ 2:217-227

10. Aalto A, Aro A, Teperi J (1999) Rand-36 terveyteen liittyvän elämänlaadun mittarina: mittarin luotettavuus JA suomalaiset väestöarvot. Stakes

11. Aaronson NK, Ahmedzai S, Bergman B et al (1993) The European Organization for research and treatment of cancer QLQ-C30: a quality-of-life instrument for use in international clinical trials in oncology. JNCI J Natl Cancer Inst 85:365-376

12. Morten Boysen J, de Leeuw RJ, for the European Organization for Research and Treatment of Cancer Quality of Life Study Group et al (1999) Quality of life in head and neck cancer patients: validation of the European Organization for Research and Treatment of Cancer Quality of Life Questionnaire-H\&N35. J Clin Oncol 17:1008-1019

13. Rinkel NPM, de Leeuw IM, Langendijk JA et al (2009) The psychometric and clinical validity of the SWAL-QOL questionnaire in evaluating swallowing problems experienced by patients with oral and oropharyngeal cancer. Oral Oncol 45:67

14. Lahtinen S, Koivunen P, Ala-Kokko T et al (2019) Short- and long-term mortality and causes of death after reconstruction of cancers of the head and neck with free flaps. Br J Oral Maxillofac Surg 57:21-28

Publisher's Note Springer Nature remains neutral with regard to jurisdictional claims in published maps and institutional affiliations. 